RESENDE, Sandra Catharinne Pantaleão Factoring Cities: Paisagens urbanas a partir de discurso-diagnóstico na era financeira digital. Thésis, Rio de Janeiro, v. 5, n. 10, p. 11-27, dez. 2020

data de submissão: $16 / 08 / 2020$

data de aceite: $24 / 11 / 2020$

\section{Factoring Cities: Paisagens urbanas a partir de discurso-diagnóstico na era financeira digital}

Sandra Catharinne Pantaleão Resende

Sandra Catharinne Pantaleão RESENDE é Doutora em Arquitetura e Urbanismo; professora do PPGHIST - PUC Goiás; pantascp@gmail.com

\section{Resumo}

O artigo aborda a dinâmica urbana global, incitada pelas transformações na virada do século, visando identificar processos de modernização mais recentes e expansão a leste do planeta. São consideradas as reflexões de Rem Koolhaas sobre a lógica de consumo que orienta grande parte das intervenções urbanas, além dos processos de urbanização em pontos estratégicos do planeta condicionados à globalização, às tecnologias de informação e ao mercado financeiro. Consideram-se os termos descritos por esse arquiteto, a saber: generic city, bigness, junkspace, COED@ e Regime $¥ € \$ \subset$. Ao articulá-los, é possível traçar características da urbanização mais recente seja pela intervenção ou a expansão de cidades globais; cidades novas, especialmente no Oriente Médio e na Ásia, além da formação de um continuum espacial que alavanca e orienta grande parte da prática arquitetônica atual. Para fins de desenvolvimento da pesquisa, são apresentadas questões sobre a cidade contemporânea e seus desdobramentos na voz de Rem Koolhaas (1995; 2001a; 2001b; 2004), visando aproximar suas percepções a de outros autores como Soja $(2000 ; 2011)$ e Vàzquez $(2004 ;$ 2016), seguidas por reflexões sobre o processo recente de urbanização na China, com destaque à região do Delta do Rio Pérola (PRD).

Palavras-chave: Cidades contemporâneas, Rem Koolhaas, discurso-diagnóstico, Regime $¥ € \$ \odot$, era financeira-digital.

\begin{abstract}
This paper presents the global urban dynamic by the transformations of the recent changes and new century. The proposal is identifying the characteristics of the most recent modernization process considering the Rem Koolhaas' reflections about the consumption logic that guides most urban interventions. In addition to the urbanization process in strategic points of the planet conditioned to globalization, information technologies and the financial market. The Koolhaas' terms describe them like Generic City, Bigness, Junkspace, COED@ e Regime $¥ € \$ \subset$. By articulating them, it is possible to trace characteristics of the most recent urbanization, either through the intervention or the expansion of global cities; new cities, especially in the Middle East and Asia, in addition to the formation of a spatial continuum that leverages and guides much of today's architectural practice. For research development purposes, reflections on the contemporary city and its consequences are presented in the voice of Rem Koolhaas (1995; 2001a; 2001b; 2004), aiming to bring their perceptions closer to that of other authors such as Soja (2000; 2011) and Vàzquez (2004; 2016), followed by reflections on the recent urbanization process in China, with emphasis on the Pearl River Delta (PRD).

Keywords: Contemporary cities, Rem Koolhaas, discourse-diagnostic, The Regime of the $¥ € \$ \odot$, digital financial era.

\section{Resumen}

El artículo presenta la dinámica urbana a nivel global incitada por las transformaciones cuyo objetivo es identificar las características del proceso de modernización a la luz del siglo XXI. Se consideran las reflexiones de Rem Koolhaas sobre la lógica de consumo
\end{abstract}


que guía la mayoría de las intervenciones urbanas, además de los procesos de urbanización en puntos estratégicos del planeta condicionados a la globalización, las tecnologías de la información y el mercado financiero. Se consideran los términos descritos por ese arquitecto, a saber: ciudad genérica, grandeza, espacio basura, COED@ y Régimen $¥ € \$ \subset$. Al articularlos, es posible rastrear características de la urbanización más reciente, sea a través de la intervención o la expansión de ciudades globales; nuevas ciudades, especialmente en Oriente Medio y Asia, además de la formación de un continuum espacial que aprovecha y guía gran parte de la práctica arquitectónica actual. Para el desarrollo de la investigación, las reflexiones sobre la ciudad contemporánea y sus consecuencias se presentan en la voz de Rem Koolhaas (1995; 2001a; 2001b; 2004), con el objetivo de acercar sus percepciones a las de otros autores como Soja (2000; 2011) y Vàzquez (2004; 2016), seguido de reflexiones sobre el reciente proceso de urbanización en China, con mas propiedad en la región del Delta del Rio Perla.

Palabras-clave: Ciudades contemporáneas, Rem Koolhaas, discurso-diagnóstico, Régimen de $¥ € \$ \subset$, era financiera digital

\section{Introdução}

A $s$ recentes modernizações e diferentes modos de urbanização, em escala global, associados ao campo ampliado da arquitetura são foco de discussão dessa pesquisa, à medida que os projetos de grande escala prenunciam interdependências entre edifícios e espaços livres de uso público, além das relações com as tecnologias digitais, formação de continuum espacial articulado ao capital financeiro.

À medida que as cidades passam por transformações ou cidades novas são planejadas, observa-se que o exercício de projetação considera as diversas escalas que redefinem a forma urbana. Vàzquez (2004) retrata esse processo como uma sobreposição de camadas que ora voltam-se para questões ambientais, ora ressaltam aspectos histórico-culturais ou ainda por retratarem fenômenos que alteram ou remodelam a forma urbana.

A discussão se apoia nas posturas críticas dos anos 1980, que levaram à ampliação do campo de atuação do arquiteto e a revisitar o Movimento Moderno, com destaque ao arquiteto Rem Koolhaas (1944-). Seu protagonismo na cena arquitetônica ocorreu desde o concurso promovido pela Revista Casabella (1972), sua inusitada proposta para a Bienal de Veneza (1980), levando-o a se distanciar das visões pós-modernas vigentes à época e o aproximando dos preceitos modernistas ao revisitar termos como destruição criativa e tábula rasa.

Rem Koolhaas (1998) abordou temas relativos ao impacto da tecnologia de informação, resultando na elaboração de diagramas e diagnósticos. Esses, por sua 
Período entre 1990-2003, fruto da queda do Muro de Berlim e o avanço da urbanização para leste, considerando cidades chinesas e a espetacularização no Oriente Médio. vez, possibilitariam definir "um novo pragmatismo" ou como as coisas deveriam ser feitas, distanciando-o do método tipológico vigente à epoca. Para Rajchman (1998) trata-se de uma postura que vislumbrava múltiplos futuros desconhecidos, uma vez que revelavam imagens não existentes ou por ser um processo porvir ou a ser inventado. Um olhar em que, para formular propostas de intervenção e produção da forma urbana em suas mais diversas escalas, a teoria é uma forma de prática projetual. Os diagramas, como ferramentas de análise, diagnóstico e proposição de intervenções, possibilitariam mobilizar e conectar dados, convertidos em informações conforme o crescimento entorno de novas questões ou pela necessidade de responder a essas novas condições.

A compreensão desse método analítico e projetivo se expressa no projeto China's Pearl River Delta (PRD), coordenado por Rem Koolhaas e vinculado à pesquisa Harvard Project on the City, a partir da visita de campo e orientação de seus alunos. A articulação de dados e fenômenos sociais, políticos, econômicos, culturais passam a ser representados como pura informação, representada por gráficos. A sistematização dos dados e sua conversão em informações estabeleceria um novo paradigma, quer, por um lado a validade da prática atual em produzir formulários ou indicar modificações de como estes deveriam ser elaborados. Nesse sentido, a metodologia proposta por Rem Koolhaas permite uma reflexão sobre o termo pragmatismo crítico e suas abordagens acerca da intensa urbanização que antecede o século XXI, notadamente ao lançar olhares sobre a porção mais a leste do planeta.

Para o desenvolvimento deste artigo tem-se a postura de Koolhaas no debate de revisão e crítica ao Movimento Moderno, visando elucidar seus principais termos quanto à condição urbana contemporânea e as interlocuções com outros autores, com destaque às de Vàzquez $(2004 ;$ 2016) e Soja (2000; 2011). Em seguida, são identificadas as práticas arquitetônicas contemporâneas que se aproximam do termo Regime $¥ € \$^{\oplus 1}$ (KOOLHAAS, 2004) e os desdobramentos da urbanização globalizada e acelerada na China, com destaque a PRD e ao sul da China.

\section{Rem Koolhaas: discurso-diagnóstico e modernizações das cidades no século XXI}

Os anos 1960 são conhecidos como período de revisão dos preceitos iluministas, uma vez que a própria definição de modernidade foi posta em xeque. Publi- 
cações em diversas áreas das ciências humanas e sociais abalaram a visão de mundo respaldada pelo progresso contínuo e avanços científicos, resultando na superação do paradigma tecnológico-psicológico ${ }^{2}$ pelo paradigma estruturalista na arquitetura e urbanismo (SOLÀ-MORALES, 1999). Aos arquitetos desse período interessava reformular as bases conceituais da disciplina e delimitar seu corpus teórico, muitas vezes distanciando-se do engajamento social, proposto pelo movimento anterior em favor de uma cientificidade orientada pelas relações entre autonomia e história.

Entre as mais diversas posturas e influências de outros campos disciplinares, o tema "cidade histórica existente" foi mais expressivo, vinculado às questões de memória, identidade, tradição e lugar, demarcando o historicismo pós-moderno cujo destaque ocorreu entre 1960-1980, tendo em vista as publicações e exposições decorrentes. Um período de questionamento aos fundamentos do Movimento Moderno, principalmente pela rejeição ao funcionalismo e da pretensão de ordenar e higienizar o espaço urbano. Aos críticos interessava mais associar as bases racionais da arquitetura e urbanismo à capacidade de transmissão de mensagens e informações por meio das formas arquitetônicas e/ou urbanas, muitas vezes atreladas à história e à linguagem clássica. A linguística e o estruturalismo instigaram os arquitetos a desenvolver o vocabulário da disciplina: a forma estaria associada ao significante e o conteúdo ao significado.

Segundo Nesbitt (1996), os tratados e os manifestos foram recursos linguísticos para a propagação de novos discursos e deslocamentos de sentidos. A dispersão de posturas e reflexões sobre o sentido da disciplina indicam os enunciados da época: a definição de sua essência e de seus limites e repensar o papel da arquitetura mediante a intensificação da vida urbana. Outra questão que atravessa os discursos, seja pelo dito ou pelo não dito, está no equilíbrio entre tradição e inovação; entre espaço edificado e natureza (artificial e natural); entre práticas sociais e poder simbólico.

A proposta de Aldo Rossi foi importante para renovação dos métodos de leitura e análise das cidades, conferindo-Ihe, como reporta Vázquez (2004), uma continuidade aos discursos culturalistas (CHOAY, 1965) e foi bastante disseminada como estratégias de intervenção, principalmente nas áreas preexistentes e tecidos urbanos consolidados.

Lado a lado com Aldo Rossi, é possível também evidenciar as propostas de Robert Venturi, que adota o
O Movimento Moderno, segundo Solà-Morales (1999), apoiou-se no paradigma tecnológico-psicológico e legitimou o ordenamento, a salubridade e a higiene como premissas para intervir ou construir o espaço edificado (SECCHI, 2006), com destaque ao papel de herói dado ao arquiteto, respaldado pela cientificidade do racionalismo e do funcionalismo aos moldes corbusianos. 
tipo com outras possibilidades de interpretação. Alinhado às mudanças da sociedade de massa para a de consumo, esse arquiteto buscou apreender a dinâmica das cidades norte-americanas. Há uma espécie de reinvenção do tipo: o pato e o galpão decorado que retratam a vida metropolitana, em que ora a forma se sobrepõe ao programa do edifício; ora a função se expressa como o sistema preponderante sobre os demais. Uma crítica fundamentada nas interpretações da vida cotidiana, distanciando-se do resgate da memória coletiva proposto por Aldo Rossi.

Antes de trabalhar o espaço urbano em Learning from Las Vesgas (1972), Venturi elaborou um manifesto contra a linguagem reducionista da arquitetura moderna, expresso em Complexidade e Contradição em arquitetura (1966), ressaltando o poder comunicativo da arquitetura enquanto linguagem. As impressões de Robert Venturi indicam uma inclinação ao pensamento liberal e menos ao compromisso social da arquitetura e do urbanismo, em que a experiência e percepção sensorial seriam importantes fontes para despertar a própria consciência.

Em vez de elaborar critérios para a cidade do futuro, esse período é demarcado pela análise da cidade existente, notadamente a europeia, no discurso de Aldo Rossi, e a americana, no de Robert Venturi. No entanto, conforme apontam diversos autores, o método tipológico foi perdendo vigor ao longo dos anos 1980. A disseminação, por vezes, distorcida desse método corroborou para seu declínio, à medida que as cidades passaram a ser alvo de investimentos públicos e privados e as intervenções urbanas de salvaguarda do patrimônio urbano e arquitetônico associaram-se às "cidades dos promotores" (VÀZQUEZ, 2004).

Outros livros também foram importantes para esta primeira fase de reação crítica aos dogmas modernistas. Em sua maioria ressaltavam os aspectos linguísticos e uma espécie de gramática arquitetônica, culminando em diversas análises e interpretações do espaço edificado. No entanto, eram textos que ressaltavam as características da cidade tradicional em detrimento da cidade moderna. Um dos livros que antagonizam tais configurações espaciais é Collage City (1978), de Collin Rowe e Fred Koetter, ao propor um método de análise do desenho urbano por meio do formalismo analítico que a figura-fundo possibilitaria. Suas análises revelam a necessidade de uma cidade de colisão, isto é, a mestiçagem em diferentes configurações espaciais por meio de colagem de fragmentos e utopias urbanas e sociais (MONTANER, 2007, p. 118). 
Trata-se de um método dialético de análise da cidade, que entremeia as formas tradicionais e inovadoras do tecido urbano por meio da percepção visual, relacionando cheios e vazios à ideia de densidade. As propostas de Rowe também remetem a ideia de estrutura e organizações lógicas da cidade, distinguindo os elementos constituintes de uma cidade tipo tradicional e da moderna, permitindo-Ihe a construção de pares binários para leitura e descrição do tecido urbano.

Para Montaner (1997), a visão estruturalista limitava a compreensão das dinâmicas de transformação da cidade existente, enrijecendo possibilidades de experimentação, propostas por um grupo de arquitetos vinculados ao pragmatismo crítico. Essa postura caracteriza-se pelo fortalecimento das relações entre cidade e arquitetura numa trama complexa que envolve, principalmente, globalização, sociedade técnico-informacional, cultura de massa e midiatização de espaços públicos. É nesse período, posterior aos anos 1980, que o discurso de Rem Koolhaas se apresenta com contornos mais nítidos, tendo em vista as publicações posteriores a Nova York delirante (1978).

Rem Koolhaas indica que houve uma alteração no papel da arquitetura e do urbanismo nos últimos 40 anos. A dissolução do sujeito iluminista e, posteriormente, do objeto arquitetônico são acentuadas em seu discurso verbal e não-verbal. Pela escritura (DERRIDA, 1973), Rem Koolhaas apresenta um outro sujeito, que se coloca como ator histórico ao colidir com as proposições metodológicas da Escola de Veneza na própria Revista Casabella (1972) ao apontar a instabilidade identitária da condição urbana contemporânea, um traço constante em suas publicações; pela prática profissional, representada pela produção coletiva de seu escritório OMA, em que aponta a arquitetura como mediação de uma cultura informacional e midiática e pela think thank AMO (Architecture Media Organization), a afirmação discursiva mediante pesquisas e sua inserção como crítico (Figura 1).

Bestky (2003, p. 25) comenta que Rem Koolhaas reivindica uma terceira via, abordando as condições urbanas entremeadas à globalização, ao capital especulativo e ao consumo de massa. Para ele, Koolhaas coloca-se numa posição crítica, sendo produtor, manipulador e impulsionador de dados convertidos em imagens, que se tornam sua própria consciência. Essa postura não decorre da sua dificuldade em projetar edifícios ou porque a arquitetura tenha perdido seu espaço. Antes de tudo, o atual contexto revela aproximações da arquitetura com branding, assinatura de 


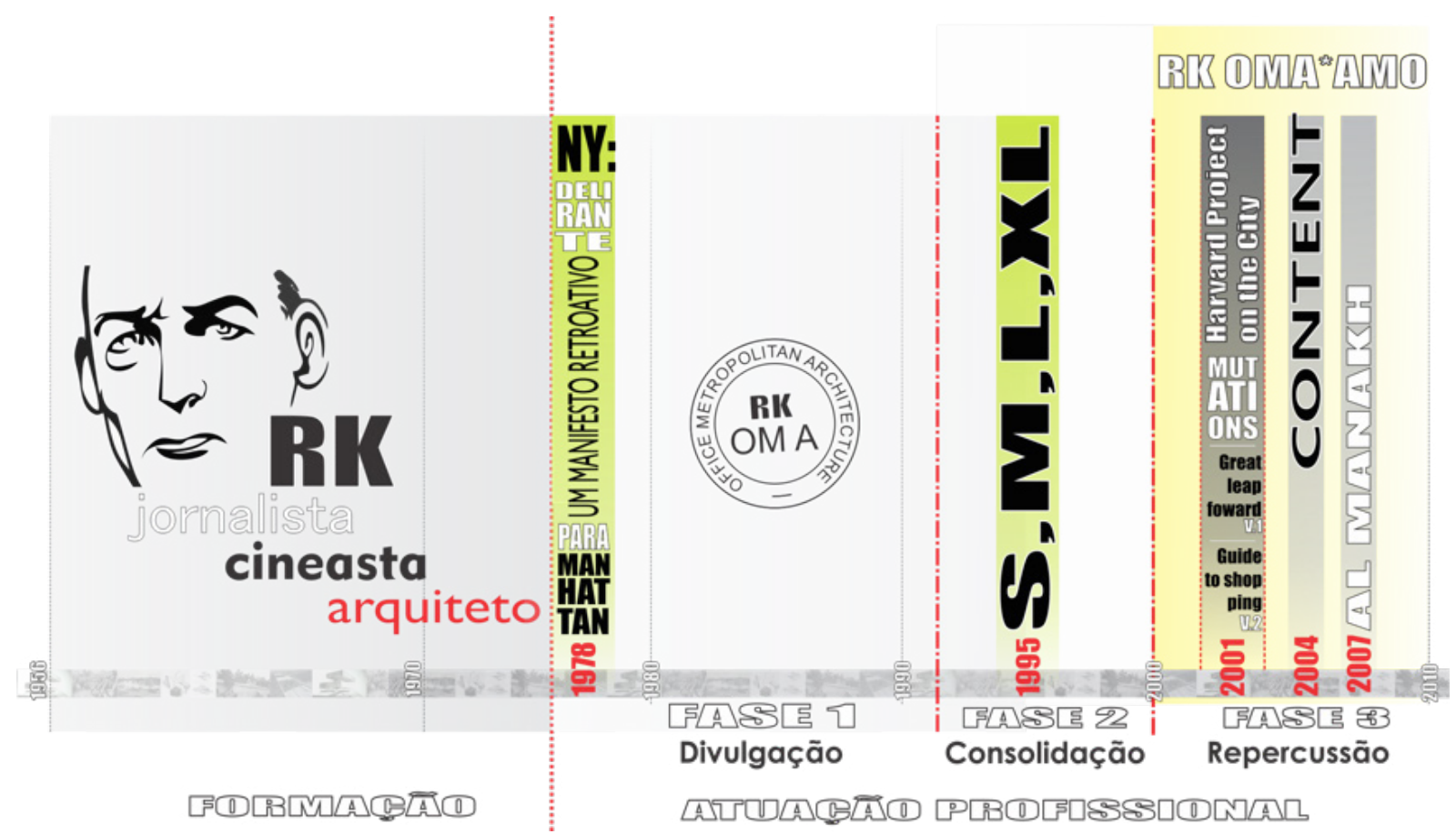

Figura 1

Fases da atuação profissional de Rem Koolhaas, OMA e AMO (1975-2015).

Fonte: Elaborado pela autora, 2015

peças exclusivas, imagens midiáticas e público, levando a novas possibilidades de trabalho, respaldadas por uma escrita e proposições mais práticas. E complementa: "[...] Rem Koolhaas tem usado a imagem da arquitetura para produzir uma arquitetura convincente de imagem". (BETSKY, 2003, p. 39) [tradução nossa] Suas abordagens também apontam a desestabilização da estrutura urbana em sua longa duração histórica. Compreender a dissolução da cidade tradicional aos moldes ocidentais, permite-Ihe identificar as possíveis áreas para aprimorar a atuação de sua empresa (OMA*AMO) numa contingência histórica de modernizações. Fragmentos que convivem num mesmo espaço, mas em diferentes estágios cronológicos, conforme as interações do capitalismo tardio em escala global. Para tanto, recorre-se ao discurso diagnóstico, por meio de diagramas e análises da condição existente.

Não obstante, a arquitetura relaciona-se diretamente ao capital financeiro e vincula-se às reestruturações econômicas (SOJA, 2000), dinamizando-se. Pode-se dizer que para Rem Koolhaas, a arquitetura é um meio de investimento e cabe ao arquiteto ser o mediador, enxergar as oportunidades para instruir investidores quanto às expectativas de retorno - seja de ordem política, econômica ou cultural. Com isso, seu discurso aproxima-se de diagnósticos para que possa propagar a atuação da OMA*AMO no mercado global e fixar-se como parte do starsystem. Há uma preocupação 
também em gestão da marca, dotando-lhe de valor especulativo ou royalties.

Em suma, em sua crítica presente nos textos de $S, M$, L, XL (KOOLHAAS; MAU, 1995) assimila a dinâmica do capitalismo tardio e os efeitos da globalização em Generic City; discorre sobre a cultura da congestão e evidencia a heterogeneidade em Tabula Rasa Revisited e Bigness e, por fim, observa o tempo de um agora absoluto em que a disciplina arquitetônica se fundamenta numa busca incessante pelo prazer descartável ou Junkspace (KOOLHAAS, 2001).

Pode-se dizer que a pesquisa Harvard Project on the City amplifica seus questionamentos de $\mathrm{S}, \mathrm{M}, \mathrm{L}, \mathrm{XL}$ (Figura 2), com maior ênfase às escalas Large e Extra Large, visto que possibilitam associar termos presentes nesta publicação à ideia posterior de Regime $¥ € \$^{\odot}$ (Figura 3).
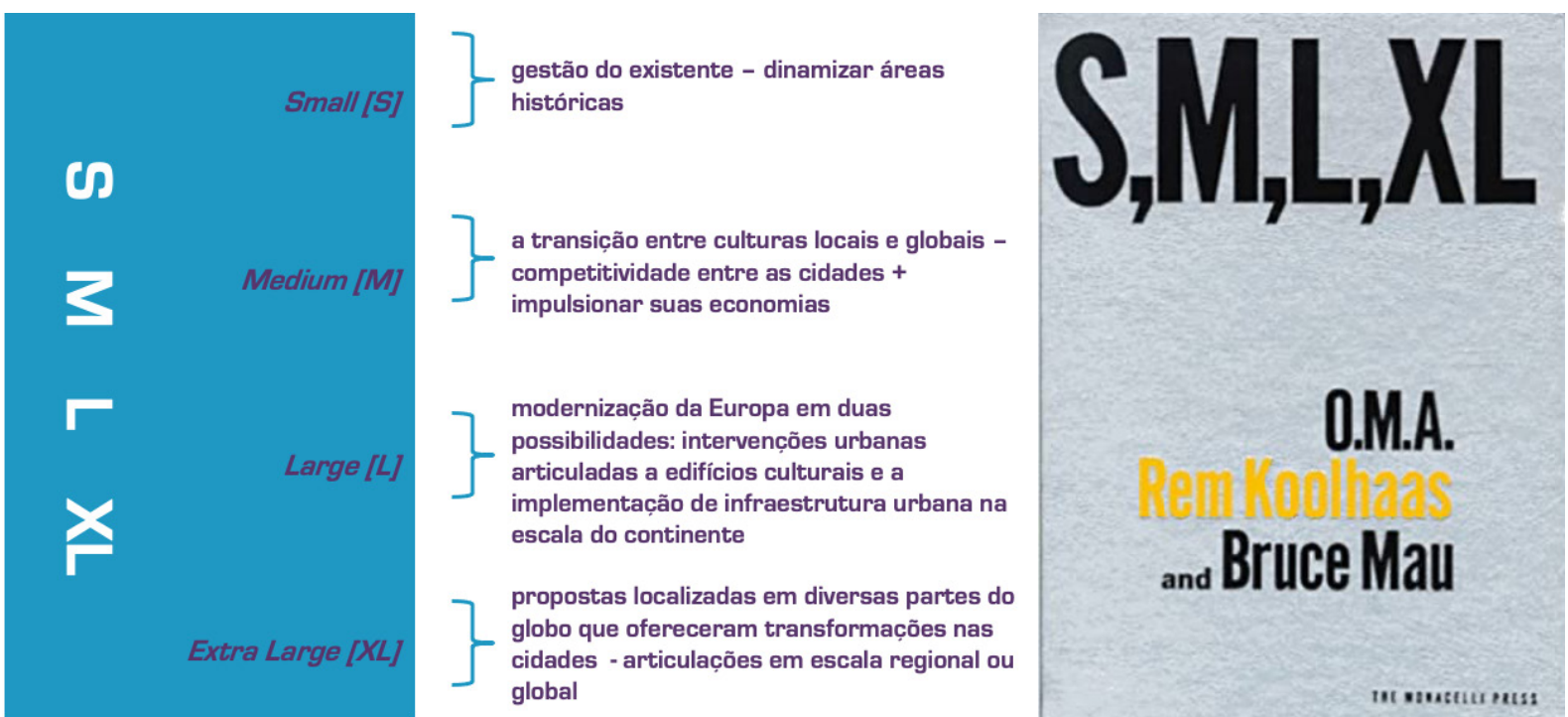

Figura 2

Interpretação das escalas $\mathrm{S}, \mathrm{M}, \mathrm{L}, \mathrm{XL}$ e sua relação com a preservação e transformação das cidades Fonte: Elaborado pela autora, 2016

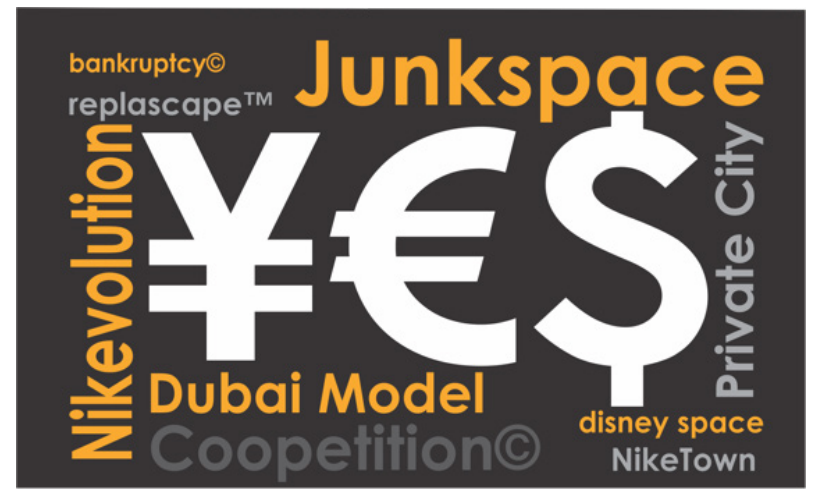

Figura 3

Termos selecionados para caracterizar Regime $¥ € \$$

Fonte: Elaborado pela autora, 2016 
Em específico, destaca-se Junkspace, termo que caracteriza a arquitetura descartável, vinculada ao capital especulativo e ao arranjo geográfico global; soma-se ainda, termos originários da economia e aplicados como estratégias urbanas, tais como Coopetition ${ }^{\odot} \mathrm{e}$ Bankruptcy ${ }^{\odot}$, reforçando as transformações urbanas no leste. Além destes, tem-se NikeTown ${ }^{\circ}$ relacionado a ideia de brand urbano: uma metáfora da cidade midiática a partir das campanhas publicitárias da Nike, um modelo de organização espacial que estimula o consumo.

Regime $¥ € \$^{\circ}$, por sua vez, caracteriza de um período de significativas mudanças na arquitetura e nas cidades, tendo por referência a queda do Muro de Berlim e o avanço da urbanização para leste e a recente espetacularização no Oriente Médio, além de projetos culturais e de preservação, especialmente na Europa. Significa apontar a cartografia da dinâmica global de consumo enunciando a condição urbana contemporânea entre 1989 e 2003, em que são destacadas as relações internacionais e a restruturação econômica, por sua vez, associadas a grandes projetos de intervenção urbana e à mercantilização dos museus, indexados à bolsa de valores (Figura 4).

As relações entre arquitetura e urbanismo e as condições da cultura contemporânea revelam a polarização China/Estados Unidos na disputa dos mercados globais. Na parte superior, tem-se a presença da arquite-

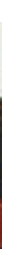

Figura 4

Cartografia do Regime $¥ € \$$ com agrupamento de informações Fonte: KOOLHAAS; MCGETRICK 2004, organizado pela autora, 2016

tura denominada drunken party - dispostos de cabeça para baixo, estão edifícios emblemáticos na Europa, assinados por arquitetos-estrelas, e os arranha-céus mais altos do mundo, em sua maioria na Ásia e, mais recentemente, no Oriente Médio. A linha vermelha demarca o crescimento da bolsa de valores Dow Jones e indica o domínio financeiro dos Estados Unidos como o principal personagem desse enredo: a "ocidentalização" da China, que também é registrada.

De modo geral, pode-se caracterizar a trajetória profissional de Rem Koolhaas à sua própria percepção 
das mudanças do último quartel do século passado, tendo em vista a confrontação ao método tipológico em que a forma urbana história era protagonista em prol de uma constatação das modernizações proeminentes em prol da própria ideia de preservação ou pela redefinição do termo tábula rasa ao constatar a sobreposição de tradição e inovação no Oriente, tornando-se uma voz dissonante por considerar as dinâmicas econômicas em seus textos.

\section{Factoring Cities: de cidades globais a urbanização regional multiescalar}

O Regime $¥ € \$^{\odot}$ aponta o rearranjo geográfico e social de um mundo globalizado, visto uma nova ordem em que forças econômicas, políticas e culturais modificam o modo de intervir e propor novas cidades. A arquitetura assume papel estratégico, resultando em projetos inéditos, espetaculares e de grande impacto visual, conforme relata Arantes (2010) ao caracterizar a era financeira digital.

Nos anos 1990-2000, Koolhaas concentrou suas pesquisas em PRD, na China, e, posteriormente, no Oriente Médio. São pontos do planeta em que emergiram cidades "modernas e ocidentais" numa frenética busca pela inserção na economia global, ou em suas palavras, imersas no Regime $¥ € \$ \$^{\odot}$. A caracterização dessas cidades reforça o termo cidade-região de Soja (2011, p. 138) pois sua origem está na força gerativa da globalização e da nova economia, em que múltiplas escalas se articulam, com objetivo de constituir regiões e não apenas cidades, denominada por ele de "urbanização regional multiescalar e policêntrica". Ambos conceitos pretendem compreender a estrutura organizativa do continuum espacial e identificar a ressignificação ou a dissolução do termo metrópole para além da reestruturação urbana dos últimos 3040 anos, superando termos como megalópoles e cidades globais.

O Delta do Rio Pérola incita essas reflexões, pois projeta uma articulação do Sudeste da China com Hong Kong a Macau e é a maior área urbanizada do mundo, mediante uma infraestrutura financiada com capital estrangeiro desde os anos 1980, capaz de aglutinar mais de nove cidades principais e cerca de 60 milhões de residentes (80 milhões em 2030) numa área de $56.000 \mathrm{~m}^{2}$ com previsão de concentrar três dos maiores arranha-céus do mundo até 2020. Para tanto, o governo chinês propôs a formação de Zonas Especiais Econômicas (Special Economic Zones - SEZ) em PRD, aproximando as cinco cidades principais da dinâmica 
3 A pesquisa de cada uma das cidades ficou a cargo de um dos estudantes de pós-graduação, cabendo a Koolhaas a direção da pesquisa, cuja coordenação foi de responsabilidade de Jeffrey Inaba, resultando na publicação Project the City 1 The Great Leap Foward. de Hong Kong. Houve uma política de descentralização da produção industrial, com atividades especializadas. Apesar de ter permitido o avanço econômico da região, observam-se grandes problemas sociais, o que reforça as diferenças e os fragmentos de urbanização nas cidades pesquisadas, reforçando o termo The City of the Exarcebated Difference - $\operatorname{COED}^{\circ}$ : a condição urbana resultante de Regime $¥ € \$$. Há uma persistente competitividade entre cada um dos pontos que conformam a cidade-região e todos os seus elementos. A cada mudança em algum dos componentes, haveria ajustes conceituais dentro do sistema $\operatorname{COED}^{\odot}$, revelando uma interdependência entre as cidades e não apenas entre suas partes, levando-os a estudar a região e suas cidades.

As cinco cidades estudadas por Koolhaas ${ }^{3}$ e seus alunos representam os avanços econômicos da China a partir de meados dos anos 1980, quando o país se abriu ao mercado globalizado. Cada uma destas cidades é apresentada por verbetes, permitindo identificar seu papel na dinâmica urbana de PRD (Quadro 01).

\begin{tabular}{|c|c|c|}
\hline \multicolumn{3}{|c|}{$\begin{array}{l}\text { Sistematização da pesquisa Great Leap Forward: caracterização das cidades por verbetes conforme } \\
\text { as especificidades de cada uma em PRD. }\end{array}$} \\
\hline Cidade & Verbetes & Autores \\
\hline Shenzen & Ideology $\subset+$ Architecture $\subseteq$ & Mihai Craciun e Nancy Lin \\
\hline Dongguan & Money@ & Stephanie Smith \\
\hline Zhuhai & Landscape $\subset$ & Kate Orff \\
\hline Guangzhou & Policy (C) & Yuyang Liu \\
\hline Pearl River Delta & Infrastructure $@$ & Bernard Chang \\
\hline
\end{tabular}

Quadro 1

Organização da pesquisa Project on the City I: Great Leap Forward

Fonte: Koolhaas et. al. (2001b), organizado pela autora, 2015

A análise de Shenzhen é feita pelos verbetes Ideolo$g y^{\circ}$ e Architecture $^{\circ}$, numa relação direta entre modernização e mudanças no território, sendo a cidade em que as invocações e edifícios de maior impacto são implantados. O verbete Money $^{\odot}$ reporta a Dongguan, devido à dinamização da economia de mercado e à transformação social dessa cidade, revelando-se a mais cosmopolita da região. O verbete Landscape ${ }^{\circ}$ remete a Zhuhai, modificando a paisagem existente de tal forma a não haver distinção entre cidade e campo ou a coexistência de ambos numa mesma paisagem. A cidade de Guangzhou está relacionada ao verbete Policy $^{\odot}$, que ressalta as decisões administrativas e públicas da região. Ao final, o verbete Infrastructure ${ }^{\odot}$ demonstra a articulação entre as cidades e a integra- 
ção com Hong Kong e Macau, visto as parcerias público-privadas firmadas para alavancar a economia e urbanização de PRD.

Shenzen é uma das experiências mais expressivas de crescimento urbano da China, caracterizando a urbanização regional multiescalar ao se tornar uma das principais sedes das indústrias de tecnologia do mundo, como a Foxcoon City, fabricante de componentes eletrônicos para a Apple. Mais do que uma simples fábrica, essa empresa mais se assemelha a cidades, revelando o processo de fabricar cidades (factoring $\mathrm{ci}$ ties) em meio a áreas até então rurais. O termo factoring cities alude ao conceito de Regime $¥ € \$ \odot$ por indicar como as transações financeiras a nível global são incitadas pelas tecnologias de informação, refletindo na urbanização acelerada de PRD. Os espaços resultantes desse processo se deslocam do lugar e se conectam às sedes das empresas para as quais fornecem os insumos tecnológicos mediante uma mão-de-obra mais barata e com menos regulamentações trabalhistas.

Para Al Stefan (2012), o crescimento de Shenzhen ocorreu muito rapidamente e sem que houvesse uma preocupação em diferenciar as áreas urbanas das rurais como fora nos anos 1950 . Conforme as pesquisas coordenadas por Koolhaas (2001), Shenzhen representa o principal nó de articulação entre Hong Kong e Macau, além de incitar a política de urbanização com investimentos estrangeiros em infraestrutura que levaram à inserção e maior presença da China no mercado global desde fins dos anos 1980. A modernização de PRD expressa os interesses políticos locais, com o objetivo de promover o desenvolvimento por meio da urbanização e da [re]criação de cidades novas ou de Generic City.

As configurações espaciais adotadas são confrontadas às formas urbanas ocidentais e tradicionais. Em Shenzhen prevalece características de cidades lineares, facilitando seu papel de nó estratégico na formação de um continuum espacial de alcance global, acentuado pela indistinção entre áreas urbanas e rurais que coexistem em grande parte desse processo, o que resulta no verbete $\mathrm{COED}^{\odot}$. Durante o período pesquisado, observou-se que Shenzhen detinha de uma alta demanda por novos projetos. Estes foram produzidos por escritórios estrangeiros, visto a sobrecarga de trabalho dos escritórios locais e os interesses locais de atrair investimento do capital especulativo para a região a partir de arquiteturas espetaculares e com assinaturas de arquitetos internacionalmente co- 
nhecidos. Nesse sentido, observa-se também o sentido do investimento do capital especulativo na criação de imagens atrativas e que pudessem representar a ascensão da China a nível internacional, tornando a arquitetura a própria imagem de modernização.

PRD apresenta uma heterogeneidade de paisagens que ainda não inventadas, não só pelas cidades, mas por formar uma cidade-região (SOJA, 2011), uma vez que torna-se um nó a partir da relação entre Macau, Hong Kong e Shenzhen. Nas palavras de Koolhaas, Regime $¥ € \$^{\oplus}$ produz uma persistente competitividade entre cada um e todos os elementos dessa condição urbana, reforçando o verbete $\operatorname{COED}^{\odot}$. Como exemplo Koolhaas cita: "[...] se Hong Kong tornar-se mais densa e mais urbana, Zuhai teria que se tornar mais suburbana para manter o contraste entre elas $[\ldots]$ " (KOOLHAAS, 2001, p. 184).

A morfologia desse conjunto de cidades amplifica a complexidade da atuação do arquiteto e urbanista, sendo necessária a compreensão dos dados existentes nessa dinâmica, uma cartografia que configura o Regime $¥ € \$^{\odot}$, vinculada a um sistema econômico global. Em sua maioria, são projetos de intervenção urbana ou edifícios emblemáticos, que visam, alavancar os investimentos como produtos rentáveis. E, para que sejam sucesso, os investidores e/ou a gestão pública recorrem aos starsystem arquitetónico. Isso é percetível não só pela reputação que cada um deles adquirem como sua repercussão no próprio campo disciplinar e na relação custo-benefício.

Para Arantes (2000), a cidade é vista como growth machine: um empreendimento que visa expandir a economia local e aumentar suas riquezas a partir de políticas urbanas. As cidades tornaram-se terreno fértil para investimentos, um produto lucrativo, colocando em questionamento as intervenções urbanas do século passado.

O legado das Olimpíadas de Pequim permitiu uma enorme atualização de hardware, garantindo a segurança da cidade e uma série de projetos arquitetônicos contemporâneos, que, nas palavras de Koolhaas (1999) soam espaços extravagantes, arquitetonicamente ambiciosos e absolutamente memoráveis em que ressoam os interesses dos clientes públicos e/ou privados e os valores das corporações.

A leitura de PRD permite constatar um quadro de profundas mudanças e a necessidade de empregar novos termos para descrever e caracterizar a forma urbana, 
ampliando os horizontes de análise e, por conseguinte, oferecer elementos para o debate da paisagem urbana, seja a nível local ou global. Desse modo, a pesquisa concentrou-se em discutir a trama urbana sob um panorama de intensificação da globalização, da revolução técnico-informacional e do neoliberalismo, por meio da definição de Regime $¥ € \$^{\odot}$. Considera-se que esse termo possibilita avaliar factoring cities, isto é, a produção de cidades que se alastram em diferentes partes do planeta, alicerçadas por uma urbanização intensa e em larga escala conforme os interesses do capital especulativo na era digital financeira.

\section{Considerações Finais}

O período retratado é marcado pela lógica do mercado financeiro, alicerçado pelo controle do espaço que apontam dois modos de urbanização: na China, as estratégias para formação de uma urbanização multiescalar (SOJA, 2011), conformando a região de PRD e as relações entre Macau, Hong Kong e o continuum espacial por meio de cidades fábricas, isto é, em meio a áreas rurais tem-se a instalação de grandes grupos financeiros, que passam a conduzir a produção de roupas, aparatos tecnológicos entre outros para distribuição a nível global. A transformação essa região chinesa (AL STEFAN, 2012) caracteriza os processos de modernização do século XXI e trazem a luz reflexões sobre os termos apontados por Rem Koolhaas (1995; $2001 ; 2004)$.

Para Vàzquez (2016), são metápoles que apontam as transformações vindouras, as quais os arquitetos, como Rem Koolhaas, buscam caracterizar e compreender sincronamente. Para o autor, a cidade contemporânea configura-se como uma "criatura incerta", uma vez que agrega variáveis econômicas, sociais, culturais e políticas complexas, cuja forma embaralha-se em espectros temporais e espaciais de difícil apreensão. Tarefa que se torna cada vez mais difícil em função da acelerada e intensa urbanização do último quartel de século e as modernizações iminente do século XXI. Sua postura reafirma o meio técnico-informacional (SANTOS, 1996) como componente de aceleração da história e para o exacerbado valor dado ao presente, reforçando as questões apontadas por Harvey (1992) quanto à compressão do espaço-tempo.

Para Muñoz (2008), essa transformação no espaço urbano é uma "urbanalização": a paisagem da cidade é tematizada como se fosse um parque temático; é a reprodução de uma arquitetura em todo o mundo, sem relação específica com a cidade ou com o entor- 
no; apenas uma colagem, visando, sobretudo, gerar renda e maior atratividade dos espaços urbanos que passaram por algum tipo de intervenção. Dessa forma, para ele, a paisagem urbana passa a não pertencer nem à cidade e tampouco ao urbano, e sim ao governo do espetáculo. Essas cidades passam a ser meramente um lugar de representação do poder, seja ele de cunho político ou de cunho econômico. No caso da China, refere-se à inserção no mundo globalizado, suscetível à lógica do capital financeiro, sendo fundamental inserir, em suas cidades, emblemáticos edifícios ocidentais, galgando à arquitetura a capacidade de apresentar, representar e expressar a modernização almejada globalmente.

A Koolhaas interessa descrever a condição urbana contemporânea em que são retratadas as mudanças cingidas sobre as cidades, em diferentes partes do globo, fincando, de certo modo, marcos temporais de reordenamento da dinâmica urbana em escala global. Sua visão acerca da cidade contemporânea, conforme aponta Vàzquez (2016), apoia-se na apreensão da lógica socioeconômica do capitalismo tardio para formular respostas técnicas capazes de orientar o desenho urbano e as práticas urbanísticas.

Nesse sentido, a história das cidades chinesas, apresentada nas pesquisas de Koolhaas, limita-se ao registro de suas ruínas: a dissolução do tempo histórico capaz de almejar uma cidade utópica do futuro ou resgatar a nostalgia do passado. Um desmantelamento das pretensões científicas conferidas ao urbanismo pelos modernos e pós-modernos e a proposição de um olhar interpretativo e pragmático às dinâmicas urbanas. Não cabe o julgamento, mas sim a constatação das transformações em curso, apreendidas por Koolhaas e seu coletivo expressado por um vocabulário próprio, que busca descrever a condição urbana contemporânea. Essa, por sua vez, torna-se possível a partir da somatória entre globalização, tecnologia da informação e consumo, elementos que pode ser, respectivamente, indicados pelo tripé Bigness, Generic City e Junskpace. Entre os termos e verbetes, essas são tidas como palavras-chave, das quais desdobram diversas possibilidades interpretativas sem um significado estanque ou cristalizado.

As percepções de Rem Koolhaas concentram-se em registrar e analisar as transformações dos últimos quarentas anos, abordando o impacto do trinômio: globalização, tecnologias de informação e consumo de massa como elementos inerentes à compreensão da dinâmica urbana em escala planetária. Suas publica- 
ções mais recentes e coordenadas pela AMO apresentam o fortalecimento do Oriente, em especial a Ásia, na reconfiguração das forças do capitalismo tardio em que as cidades passam de lócus de compras para a constituição do brand urbano. Essa condição contemporânea apoia-se também na consolidação da urbanização regional e sua intensificação, reverberando na dissolução das fronteiras dos Estados-Nação e na constituição de espaços edificados cosmopolitas, muitas vezes sem preservação da identidade, memória e cultura. Ao contrário, reforçam o papel imagético da arquitetura e suas relações com as dinâmicas econômicas, reveladas pela intensificação da urbana acelerada e intensa desse século.

\section{Referências}

AL, Stefan. Factory Towns of South of China. Hong Kong: Hong Kong University Press, 2012.

ARANTES, Pedro Fiori. Forma, valor e renda na arquitetura contemporânea. ARS, São Paulo, v. 8, n. 16, 2010. Disponível em: <http://www.scielo.br/pdf/ars/v8n16/07.pdf>. Acesso em: 20 jan. 2013.

BETSKY, Aaron. Rem Koolhaas: the fire of manhattanism inside the iceberg of modernism. In: . What is OMA considering Rem Koolhaas and the Office for Metropolitan Architecture. Roterdã: Nai Publishers, 2003. p. 25-39.

HARVEY, David. A condição pós-moderna. Tradução: Adail Ubirajara Sobral e Maria Stela Gonçalves. São Paulo: Edições Loyola, 1992.

KOOLHAAS, Rem. Delirious New York. Nova York: Monacelli Press, 1978.

KOOLHAAS, Rem; MAU, Bruce. S, M, L, XL. Nova York: Monacelli Press, 1995.

KOOLHAAS, Rem; MCGETRICK, Brendan. Content: triumph of realization. Koln: Taschen, 2004.

KOOLHAAS, Rem; ZENGHELIS, Elia. Exodus, o i prigionieri volontari dell'architettura/Exodus, or the voluntary prisoners of architecture. Casabella, Milão, n. 378, p. 42-45, jun. 1973.

KOOLHAAS, Rem et al. Harvard Design School Project on the City I: great leap forward. Koln: Taschen, 2001b. $2001 a$

Harvard Design School Project on the City II: guide to shopping. Koln: Taschen,

MUÑOZ, Francesc. Urbanalización: paisajes comunes, lugares globales. Barcelona: Gustavo Gili, 2008.

SANTOS, Milton. A natureza do espaço: técnica e tempo, razão e emoção. São Paulo: Hucitec, 1996. 
SOJA, Edward W. Postmetropolis: critical studies of cities and regions. Oxford: Basil Blackwell, 2000.

. Regional urbanization and the end of the metropolis era. In: BRIDGE, Gary; WATSON, Sophie. A Companion to the City. Oxford and Malden, MA: Blackwell Publishing Ltd, 2011, p. 679-689.

VÁZQUEZ, Carlos García. Teorías e historia de la ciudad contemporânea. Editorial Gustavo Gili: Barcelona, 2016.

. Ciudad Hojaldre. Editorial Gustavo Gili: Barcelona, 2004. 